\title{
Itraconazole inhibits the proliferation of gastric cancer cells in vitro and improves patient survival
}

\author{
KE LAN, RON YAN, KUN ZHU, WENHAN LI, ZISEN XU, CHENGXUE DANG and KANG LI \\ Department of Oncology, The First Affiliated Hospital, Xi'an Jiaotong University College of Medicine, \\ Xi'an, Shaanxi 710061, P.R. China
}

Received September 25, 2017; Accepted February 28, 2018

DOI: $10.3892 / \mathrm{ol} .2018 .9072$

\begin{abstract}
Itraconazole is a Food and Drug Administrationapproved antifungal drug belonging to the azole family. Recent studies reported that itraconazole has potential anticancer activity. Whether combining itraconazole with other anticancer compounds such as 5-fluorouracil (5-FU), a potent drug used in the treatment of gastric cancer, is unknown and warrants further study. In the present study, SGC-7901 gastric cancer cells were chosen to assess the anticancer effects of itraconazole in combination with 5-FU. Cell proliferation was assessed by a Cell Counting Kit- 8 assay, and apoptosis was assessed by Annexin V/propidium iodide (PI) staining and flow cytometry. Cell cycle distribution was determined by PI staining and flow cytometer. Single-cell gel electrophoresis was used to estimate DNA damage. Medical records of patients with gastric cancer were retrospectively reviewed, and the patients treated with itraconazole were selected for the present study. Itraconazole treatment inhibited the proliferation and altered cell cycle in SGC-7901 cells while promoting early apoptosis and DNA damage. These effects were promoted in cells treated with both itraconazole and 5-FU. Combination itraconazole and 5-FU treatment showed a synergetic anticancer effect in SGC-7901 cells. In vivo, itraconazole was able to improve the outcome of 5-FU-based chemotherapy. Itraconazole alone and in combination with 5-FU was able to inhibit the growth of gastric cancer in vitro, and it was able to prolong the survival of patients with gastric cancer.
\end{abstract}

\section{Introduction}

The incidence rate of gastric cancer has declined worldwide (10-20\% per decade), from being the most common cancer in 1980 to the fourth most common cancer in 2017 (1).

Correspondence to: Dr Kang Li, Department of Oncology, The First Affiliated Hospital, Xi'an Jiaotong University College of Medicine, 227 West Yanta Road, Xi'an, Shaanxi 710061, P.R. China E-mail: healthlee@gmail.com

Key words: itraconazole, 5-fluorouracil, chemotherapy, gastric cancer
Nevertheless, gastric cancer mortality still accounts for a significant proportion of all cancer mortalities (1).

Itraconazole is a Food and Drug Administration-approved antifungal drug belonging to the azole family. Itraconazole kills fungi by inhibiting lanosterol 14a-demethylase, which is essential for the conversions of lanosterol to ergosterol in fungi and lanosterol to cholesterol in humans (2). However, an increasing number of reports have revealed that itraconazole has a potential antitumor function (2-6). A number of these reports have concluded that itraconazole has potent and selective inhibitory activity on the proliferation of endothelial cells and multiple key aspects of tumor angiogenesis in vitro and in vivo $(7,8)$.

5-fluorouracil (5-FU) is widely used as a potent drug for the treatment of gastric cancer. 5-FUis a type of pyrimidine antagonist with cytotoxic mechanisms; it has the ability to incorporate its metabolites as false precursors into DNA to cause DNA instability $(9,10)$.

The purpose of the present article is to assess the effects of itraconazole on gastric cancer. In vitro experiments were performed to determine the effects of itraconazole and 5-FU alone or in combination in SGC-7901 cells. Whether itraconazole is able to affect the survival of gastric cancer patients was also assessed.

\section{Materials and methods}

Cell lines and culture. Human SGC-7901 cell lines were purchased from The Type Culture Collection of the Chinese Academy of Sciences (Shanghai, China) and grown in standard RPMI-1640 medium (Gibco; Thermo Fisher Scientific, Inc., Waltham, MA, USA) supplemented with $10 \%$ heat-inactivated fetal bovine serum (FBS; HyClone, Logan, UT, USA), $100 \mathrm{mg} / \mathrm{ml}$ streptomycin and $100 \mathrm{U} / \mathrm{ml}$ penicillin (Gibco; Thermo Fisher Scientific, Inc.) at $37^{\circ} \mathrm{C}$ in a $5 \% \mathrm{CO}_{2}$ incubator.

Cell viability assay. SGC-7901 cells were seeded into Nunclon-96-well flat bottom plates at a density of 5,000 cells per well containing $100 \mu \mathrm{l}$ growth medium per well and incubated for $24 \mathrm{~h}$. Then, the medium was replaced with $100 \mu \mathrm{l}$ fresh medium containing various concentrations of itraconazole (Xi'an Janssen Pharmaceutical, Shanxi, China) and 5-FU (Shanghai Xudong Haipu Pharmaceutical Co. Ltd, Pudong, China), alone and in combination. After $72 \mathrm{~h}$ treatment, cell 
viability was assessed by Cell Counting Kit-8 (CCK-8) assay (Beyotime Institute of Biotechnology, Haimen, China). Briefly, CCK-8 solution was added (10 $\mu \mathrm{l} /$ well), and the culture plates were stirred gently followed by incubation in $\mathrm{CO}_{2}$ incubator at $37^{\circ} \mathrm{C}$ for $2 \mathrm{~h}$. Then, the plates were measured at $450 \mathrm{~nm}$ (Multiskan FC; Thermo Fisher Scientific, Inc.). All experiments were repeated at least three times. Dose-response curves were mapped. The values were expressed as the percentage of control, medium. The $\mathrm{IC}_{50}$ values were obtained using GraphPad Prism (version 6.00; GraphPad Software, Inc., La Jolla, CA, USA).

Analysis of combined drug effects. Drug effects were assessed using the isobologram method (11-13), which is based on the median effect principle of Chou and Talalay (14), and the CalcuSyn software (version 2.1; Biosoft, Cambridge, UK). The isobologram method is a graphic description of pharmacological interactions, which is constructed by choosing a desired fractional affected cell apoptosis $(\mathrm{Fa})$. An isobologram was generated by drawing a straight line to connect Fa points that are plotted against experimentally used non-constant-ratio combinations of drug 1 (5-FU) and drug 2 (itraconazole) on $\mathrm{x}$ - and $\mathrm{y}$-axes to. Combined data points that are on the line are represented as an additive interaction, while points that were below or above the line represented synergism or antagonism, respectively.

Cell-cycle distribution assay. SGC-7901 cells $\left(5 \times 10^{5} / 2 \mathrm{ml}\right)$ were seeded in 6-well plates and treated the following day with itraconazole $(15 \mu \mathrm{M}), 5-\mathrm{FU}(4.25 \mu \mathrm{M})$ or itraconazole combined with 5-FU (traconazole $15 \mu \mathrm{M}$ : 5-FU $4.25 \mu \mathrm{M}$ ). Following incubation for an additional $72 \mathrm{~h}$, non-adherent cells were removed. The cells were trypsinized and collected. Subsequently, the cells were washed twice with PBS then resuspended in $0.5 \mathrm{ml}$ PBS and fixed in $4.5 \mathrm{ml} 70 \%$ ethanol overnight. The cells were collected by centrifugation and were resuspended in $0.2 \mathrm{mg} / \mathrm{ml}$ of propidium iodide (PI) containing $0.1 \%$ Triton X-100 and $0.1 \mathrm{mg} / \mathrm{ml}$ RNase A. Subsequently, the cell suspension was incubated for $30 \mathrm{~min}$ in the dark at room temperature and analyzed using a flow cytometer. The percentages of cells in different phases were sorted using the ModFit 5.2 program (Verity Software House, Inc., Topsham, ME, USA). The percentage of cells at each phase was obtained from three independent experiments.

Apoptosis assay by Annexin V-fluorescein isothiocyanate (FITC)/PI staining. The cells $\left(5 \times 10^{5} / 2 \mathrm{ml}\right)$ were seeded in 6 -well plates and treated on the following day with itraconazole $(15 \mu \mathrm{M}), 5-\mathrm{FU}(4.25 \mu \mathrm{M})$, or itraconazole combined with 5-FU (traconazole $15 \mu \mathrm{M}$ : 5-FU $4.25 \mu \mathrm{M}$ ). Following incubation for an additional $72 \mathrm{~h}\left(36.5^{\circ} \mathrm{C}\right)$, the adherent and floating cells were harvested, washed with PBS and stained using an Annexin V-FITC/PI kit according to the manufacturer's instructions. Apoptosis was then analyzed using the FACScan flow cytometer with 20,000 cells in each group. Data analysis was performed using the Cell Quest software (5.1, BD Biosciences, Franklin Lakes, NJ, USA). Reproducibility was checked in three independent experiments.

Single-cell gel electrophoresis assay (SCGE).DNA damage was assessed using the SCGE assay as described by Singh et al (15) and Gao et al (16) with slight modifications (electrophoresis condition: $25 \mathrm{~V}, 300 \mathrm{~mA}, 25 \mathrm{~min}$ ). The cells were cultured as aforementioned. A total of $72 \mathrm{~h}$ after treatment, the cells were harvested and resuspended with PBS. Then, $20 \mu \mathrm{l}$ cell suspension was mixed with $160 \mu 10.7 \%$ LMA (low melting point agarose) and spread onto frosted slides that were coated with $1 \%$ NMA (normal melting point agarose). After solidification at $4^{\circ} \mathrm{C}$, the slides were immersed in lysis buffer $(2.5 \mathrm{M} \mathrm{NaCl}$,

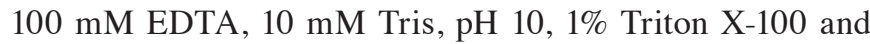
$1 \%$ sodium sarcosinate) at $4^{\circ} \mathrm{C}$ for $180 \mathrm{~min}$. The slides were subsequently placed in alkaline solution ( $1 \mathrm{mM} \mathrm{Na}{ }_{2}$ EDTA and $300 \mathrm{mM} \mathrm{NaOH}, \mathrm{pH}$ 13.0) for $20 \mathrm{~min}$, and the DNA was allowed to unwind prior to electrophoresis $(25 \mathrm{~V}, 300 \mathrm{~mA})$ for $25 \mathrm{~min}$. Subsequently, the cells were neutralized three times with $0.4 \mathrm{M}$ Tris ( $\mathrm{pH} 7.5$ ) and stained for three times with $50 \mu \mathrm{l}$ Gelview $\left(20^{\circ} \mathrm{C}, 5 \mathrm{~min}\right.$ Genestar Company, Shanghai, China, http://www.bioon.com.cn/show/index_88950.html). The images were captured using a fluorescence microscope with an excitation filter of $549 \mathrm{~nm}$ and a barrier filter of $590 \mathrm{~nm}$. All steps were carried out in the dark to prevent additional DNA damage. A total of 100 cells from each sample were selected randomly. Parameters (tail length, percentage of DNA in tail and tail moment) were analyzed by using CASP software. (CasP 1.2.3beta1, Krzysztof Końca, CaspLab.com) The genotoxicity of biomaterials was quantified.

Patients and methods. The medical records of 60 patients with histological diagnoses of advanced gastric cancer and accepted treatment at the Oncology Department of The First Affiliated Hospital of Xi'an Jiaotong University (Shaanxi, China) between January 2010 and June 2016. A total of 12 were retrospectively reviewed [18 women and 42 men, mean age: 54 (39-73) years]. The patients were included if they had received 5-FU-based chemotherapy with or without itraconazole. The clinical and pathological features of the patients were reviewed, and survival rate was calculated.

The Response Evaluation Criteria in Solid Tumors (RECIST; version 1.1) (17) was employed. The present study was approved by the Committee for the Conduct of Human Ethics Committee of the First Affiliated Hospital of Xi'an Jiaotong University, and all patients signed written informed consent forms.

Statistical analysis. Statistical comparisons between the experimental groups and the control group was performed using the chi-square test and Cox's proportional hazards regression model. The SCGE assay data was analyzed with an unpaired Student's test. Version 11.0; SPSS, Inc., Chicago, IL, USA). $\mathrm{P}<0.05$ was considered to indicate a statistically significant difference.

\section{Results}

Inhibition of proliferation of SGC-7901 cells. The inhibitory concentrations of itraconazole and 5-FU on the growth of SGC-7901 cells are indicated in Fig. 1. A potent inhibitory effect on the SGC-7901 gastric cancer cell line compared with the control was detected following treatment with $0.4 \mu \mathrm{M}$ itraconazole $(\mathrm{P}<0.05)$. Similarly, a potent inhibitory effect of 5-FU was observed compared with the control following the treatment of $0.19 \mu \mathrm{M} 5-\mathrm{FU}(\mathrm{P}<0.05)$. The $\mathrm{IC}_{50}$ values 

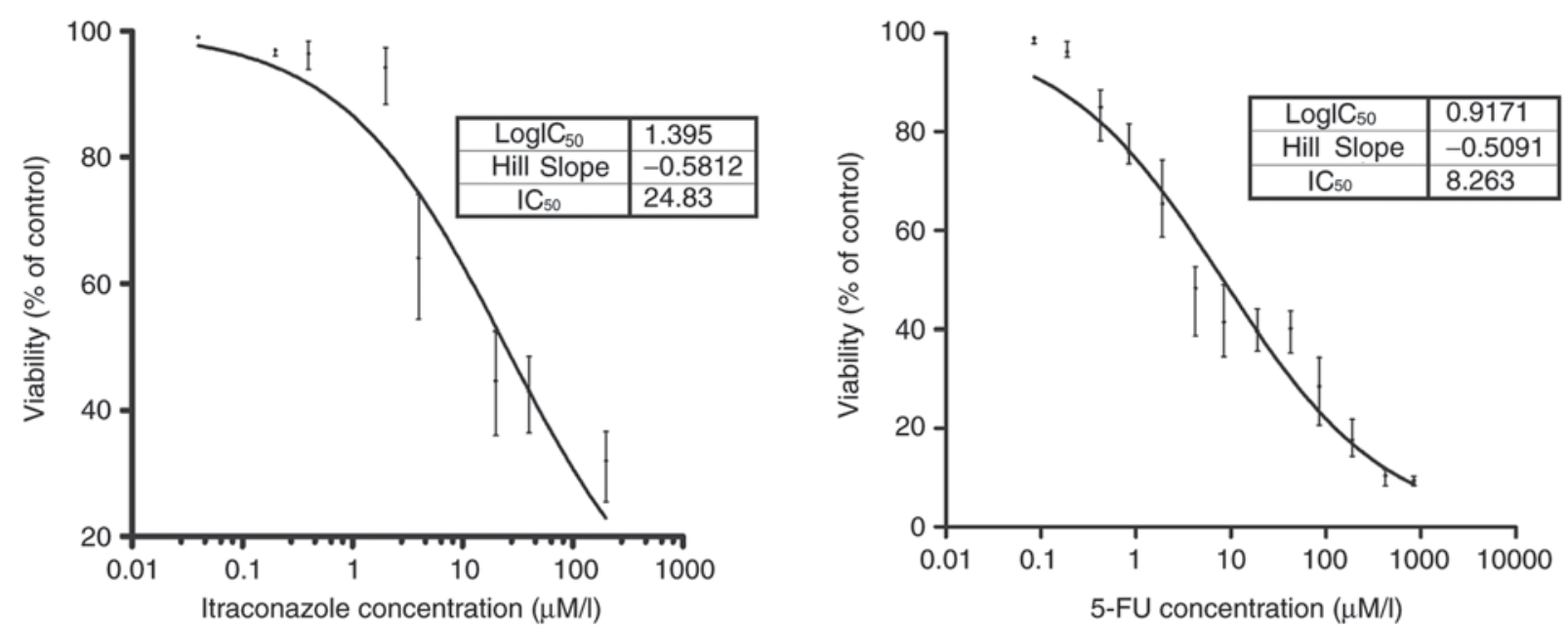

Figure 1. Proliferation in SGC-7901 cells. After $72 \mathrm{~h}$ incubation, the proliferation in SGC-7901 cells was assessed by Cell Counting Kit-8 assay. Inhibitory effects on cell viability were observed following treatment with $0.4 \mu \mathrm{M}$ itraconazole. $\mathrm{P}<0.05$. The $\mathrm{IC}_{50}$ value of itraconazole and 5 -Fu were 24.83 and $8.26 \mu \mathrm{M}$, respectively. Goodness of fit, itraconazole, $\mathrm{R}^{2}=0.919 ; 5-\mathrm{FU}, \mathrm{R}^{2}=0.961$. 5-FU, 5 -fluorouracil.

of itraconazole and 5-FU were obtained. The values were $24.83 \mu \mathrm{M}$ for itraconazole and $8.26 \mu \mathrm{M}$ for 5-FU (goodness of fit, itraconazole, $\mathrm{R}^{2}=0.919 ; 5-\mathrm{FU}, \mathrm{R}^{2}=0.961$ ).

In vitro study of itraconazole in combination with 5-FU. Based on the $\mathrm{IC}_{50}$ values as aforementioned, different ratios of itraconazole and 5-FU were selected (itraconazole: 5-FU), and different concentrations were chosen for subsequent investigation of the effect of itraconazole and 5-FU combination treatment. The CI values that provided quantitative data for the degree of drug interaction were calculated by CalcuSyn software, at Fa values of 0.50. Isobologram and median effect analysis plots were constructed (Fig. 2) for values that represent $50 \%$ growth inhibition. In the median effect analysis, the points that were below the line indicated synergism. The synergistic effect of the two drugs was more prominent when the concentrations of both drugs were below the $\mathrm{IC}_{50}$ value.

Changes in cell cycle of SGC-7901 cells. As indicated by flow cytometric analysis with propidium iodide staining, the overall proportion of cells in the G1 plus $\mathrm{S}$ phases increased compared with the control following the treatment with $15 \mu \mathrm{M}$ itraconazole and 4.25 $\mu \mathrm{M}$ 5-FU, alone or in combination (Fig. 3). However, at the same time, the proportion of cells in G2 decreased following itraconazole and 5-FU treatments (alone or in combination) compared with the control. When compared with treatment itraconazole or 5-FU alone, treating the cells with a combination of itraconazole and 5-FU was able to increase the proportion of cells in the $\mathrm{S}$ phase (Fig. 3). These findings indicate that separate treatments of itraconazole and 5-FU were able to inhibit cell cycle distribution, and the effects of the agents were increased when they are used in combination.

Apoptosis is induced in SGC-7901 cells by itraconazole and 5-FU. Flow cytometric analysis with Annexin V/PI double staining of SGC-7901 cells indicated that the percentage of early apoptotic cells was increased by treatment with $15 \mu \mathrm{M}$ itraconazole alone for $72 \mathrm{~h}$ compared with the control (Fig. 4). Treatment with $4.25 \mu \mathrm{M}$ 5-FU alone also increased the percentage of early apoptotic cells. Furthermore, when SGC-7901 cells were treated with a combination of 5-FU and itraconazole, the percentage of early apoptotic cells was increased compared with the control or treatment with 5-FU or itraconazole alone. This finding indicates that treatment of SGC-7901 cells with itraconazole and 5-FU is able to lead to early apoptosis; the effects of these agents are markedly increased when they are used in combination (Fig. 4).

Effect on DNA damage. In the Comet assay, SGC-7901 cells treated separately or with a combination of itraconazole $(15 \mu \mathrm{M})$ and 5-FU $(4.25 \mu \mathrm{M})$ were green when stained with Gelview. Normal DNA strands were observed in cells with complete nuclei, whereas fragmented DNA strands were detected in cells with marked comet tail. The length of the comet tail increased following treatment with itraconazole or 5-FU alone when compared with the control $(\mathrm{P}=0.045$ and $\mathrm{P}=0.022$; Fig. 5). Furthermore, when a combination of itraconazole and 5-FU was used, there was a significant increase in the length of the comet tail compared with treatment with itraconazole or 5-FU alone (both $\mathrm{P}<0.012$; Fig. 5).

Itraconazole is associated with the clinical outcome of patients with advanced gastric cancer. Between January 2010 and June 2016, 60 patients were eligible for inclusion in the final analyses. A summary of patient demographics is shown in Table I. All chemotherapies were 5-FU-based, with or without itraconazole. Among the patients, 22 received itraconazole therapy. Itraconazole was administered intravenously at a daily dose of 200-400 mg for 4-5 days.

Efficacy of 5-FU-based chemotherapy with itraconazole. A total of 13 patients $(59 \%$, total $=22)$ responded to chemotherapy with itraconazole, whereas $17(45 \%$, total $=38)$ responded to regimens without itraconazole $(\mathrm{P}=0.284)$. The median PFS for patients with and without itraconazole was 204 and 153 days, respectively $(\mathrm{P}=0.015)$, and the corresponding median overall survival was 382 and 301 days, respectively ( $\mathrm{P}=0.045$; Fig. 6 and Table II). 

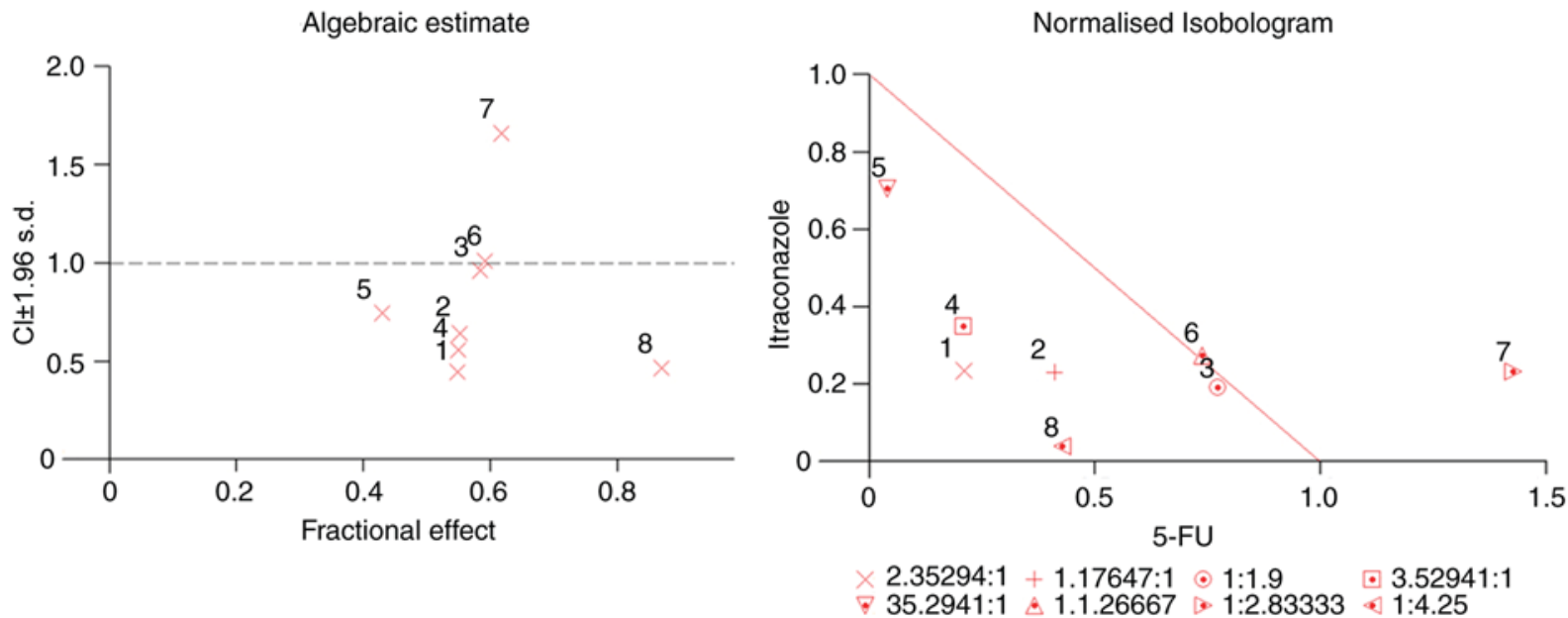

Figure 2. Evaluation of the synergistic effect of itraconazole and 5-FU complex using CalcuSyn software. Median effect analysis plot and isobologram are illustrated. The data indicated that itraconazole and 5-FU exhibited synergistic effects. Concentration of a combination of itraconazole and 5-FU ( $\mu$ M, itraconazole: 5-FU): 1) 10:4.25; 2) 10:8.5; 3) 10:19; 4) 15:4.25; 5) 15:0.425; 6) 15:19; 7) 15:42.5 and 8) 20:85. S.d. standard deviation; 5-FU, 5-fluorouracil.
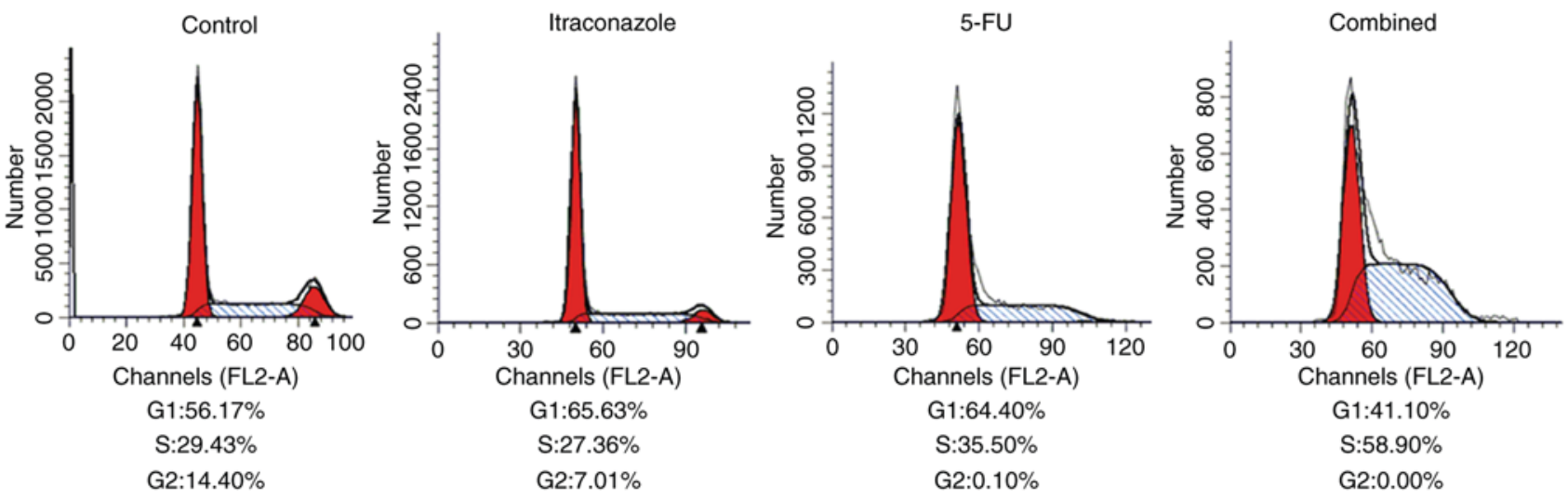

Figure 3. Effects of separate or combination treatments of itraconazole and 5-FU on the regulation of cell cycle in SGC-7901 cells. The cells were analyzed by flow cytometry. Treatment with itraconazole alone was able to inhibit the viability of SGC-7901 cells. Treatment with a combination of itraconazole and 5-FU resulted in a higher efficiency. 5-FU, 5-fluorouracil.
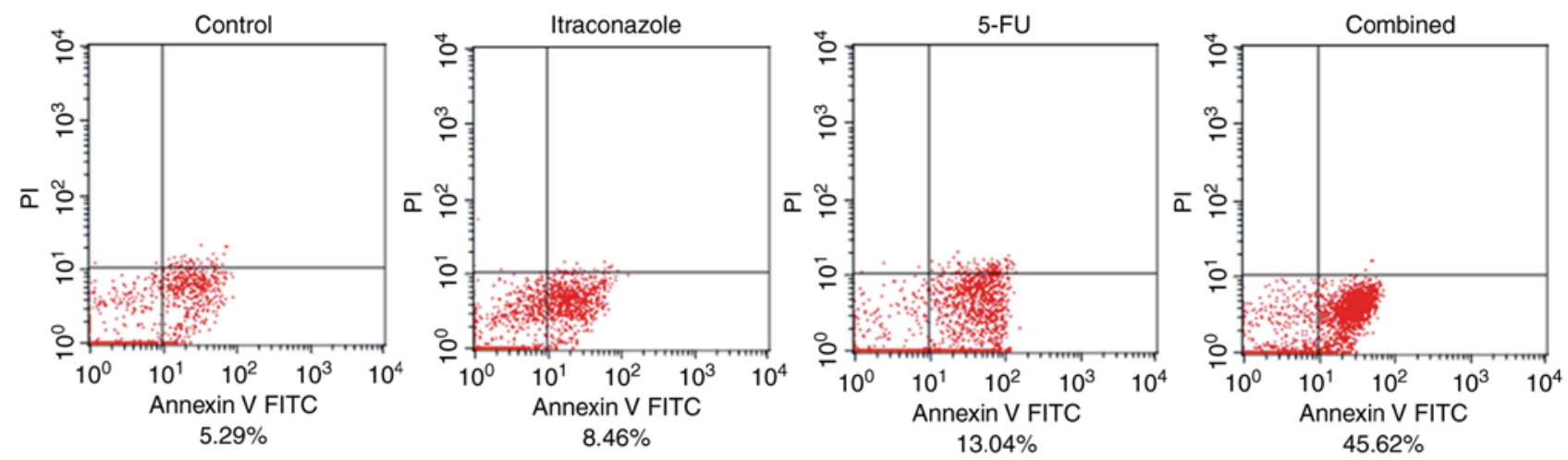

Figure 4. Effects of separate or combination treatments of itraconazole and 5-FU on the apoptosis of SGC-7901 cells. The cells were analyzed by flow cytometry. Treatment with itraconazole alone was able to increase the apoptosis of SGC-7901 cells. Notably, treatment with a combination of itraconazole and 5-FU resulted in a higher efficiency. The percentages indicate early apoptotic cells. 5-FU, 5-fluorouracil.

\section{Discussion}

While itraconazole is a traditional antifungal drug, it has been reported to inhibit angiogenesis and to have anticancer effects $(3,6)$. Although the effects of itraconazole has been demonstrated on a number of types of cancer (including, prostate cancer and non-small cell lung cancer $(7,8)$, whether itraconazole has an effect on gastric cancer remains unknown. 
Table I. Demographics of patients.

\begin{tabular}{lcc}
\hline Groups & $\begin{array}{c}\text { Itraconazole, } \\
\mathrm{n}=22\end{array}$ & $\begin{array}{c}\text { Control, } \\
\mathrm{n}=38\end{array}$ \\
\hline Median age (range) & $53(43-71)$ & $56(39-73)$ \\
Women, $\mathrm{n}(\%)$ & $6(27.2)$ & $12(31.6)$ \\
Men, n (\%) & $16(72.8)$ & $26(68.4)$ \\
ECOG PS, n (\%) & & \\
0 & $2(9.0)$ & $3(7.9)$ \\
1 & $3(17.3)$ & $30(79)$ \\
2 & $4(18.2)$ & $5(13.1)$ \\
Metastasis positive, $\mathrm{n}(\%)$ & & $8(21.1)$ \\
Histological type, $\mathrm{n}(\%)$ & $22(100.0)$ & $37(97.3)$ \\
Adenocarcinoma & $0(0.0)$ & $1(2.7)$ \\
Other & & \\
\hline
\end{tabular}

ECOG, Eastern Cooperative Oncology Group; PS, performance status.
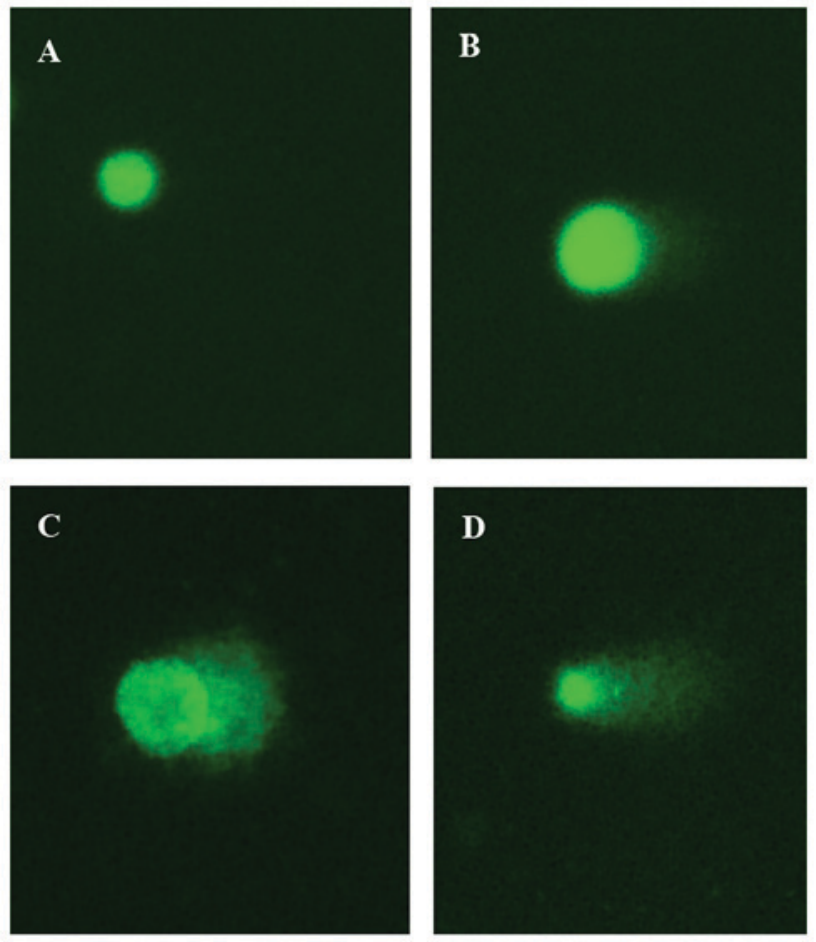

Figure 5. Effects of separate or combination treatments of itraconazole and 5-FU on DNA damage in SGC-7901 cells (x400 magnification, cells were measured by CASP software): (A) Control, (B) itraconazole, (C) 5-FU and (D) combination treatment with itraconazole and 5-FU. 5-FU, 5-fluorouracil. Control treatment was without any drugs.

5-FU is a chemotherapeutic agent, which was created $\sim 50$ years ago, but it remains in wide usage as a treatment for a variety of cancer types, either alone or in combination with other drugs (9). As such, the anticancer effects of itraconazole with 5-FU on gastric cancer in vitro and vivo are of interest for evaluation. In the present study, itraconazole exhibited marked anticancer effect on gastric cancer cells, both alone and in combination with 5-FU. Furthermore, treatment with
Table II. Factors affecting progression-free survival and overall survival.

\begin{tabular}{lccc} 
A, FPS & & & \\
\hline & P-value & HR & $95 \%$ CI \\
\hline Age & 0.336 & 0.984 & $0.951-1.017$ \\
Sex & 0.696 & 1.136 & $0.598-2.158$ \\
Histological type & 0.088 & 0.489 & $0.215-1.112$ \\
ECOG PS 1 & 0.058 & 0.291 & $0.081-1.044$ \\
ECOG PS 2 & 0.329 & 0.669 & $0.299-1.498$ \\
w/wo ITCZ & $0.015^{\mathrm{a}}$ & 0.483 & $0.268-0.870$ \\
\end{tabular}

$\mathrm{B}, \mathrm{OS}$

\begin{tabular}{lccc}
\hline & P-value & HR & $95 \%$ CI \\
\hline Age & 0.526 & 0.989 & $0.957-1.022$ \\
Sex & 0.951 & 1.022 & $0.545-1.912$ \\
Histological & 0.526 & 0.774 & $0.351-1.709$ \\
ECOG PS 1 & 0.231 & 0.484 & $0.148-1.588$ \\
ECOG PS 2 & 0.759 & 0.882 & $0.394-1.971$ \\
w/wo ITCZ & $0.045^{\mathrm{a}}$ & 0.547 & $0.304-0.987$
\end{tabular}

${ }^{\text {aP }}<0.05$ for multivariate analysis using the Cox proportional hazards model. ECOG, Eastern Cooperative Oncology Group; PS, performance status; w/wo, with or without; ITCZ, itraconazole; HR, hazard ratio; $95 \% \mathrm{CI}, 95 \%$ confidence interval.

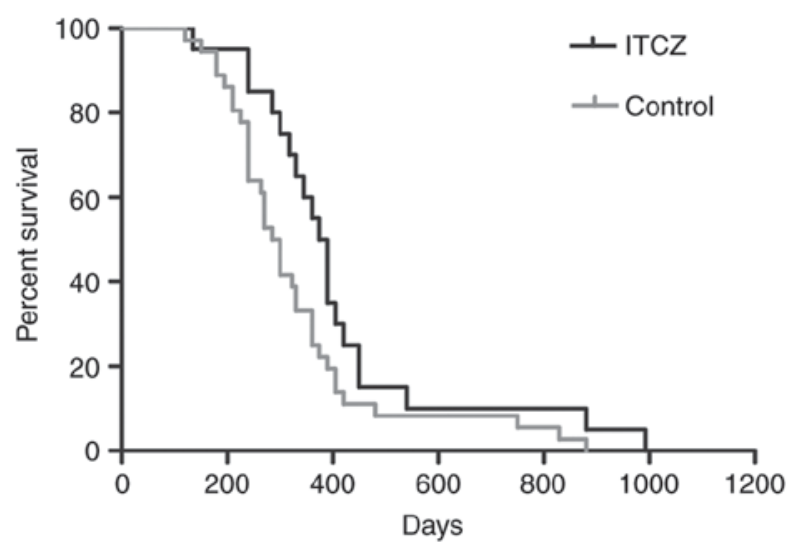

Figure 6. Patient survival for 5-FU-based chemotherapy with itraconazole. The median overall survival for patients treated with itraconazole was 382 and 301 days for the itraconazole group and control group, respectively. $\mathrm{P}=0.045$. ITCZ, itraconazole; 5-FU, 5-fluorouracil. The control group solely received 5-FU-based chemotherapy.

a combination of itraconazole and FU-based chemotherapy was indicated to improve the outcome of patients with gastric cancer.

The results of the present study were consistent with the finding of previous studies on other types of cancer (18-22). In the present study, it was demonstrated that itraconazole is able to inhibit proliferation, and DNA damage was induced by itraconazole in gastric cancer cells. Furthermore, a synergetic 
effect was observed when SGC-7901 gastric cancer cells were treated with a combination of itraconazole and 5-FU.

In Fig. 4, the apoptotic cells are mostly located in the forth quadrant. These cells were identified to be early apoptotic cells, as they did not take up PI. The concentration of itraconazole and 5-FU used and incubation time were selected following cell viability assay and analysis of a combination of the two agents. However, the drug concentration and incubation time may have not been sufficient to induce late apoptosis and potentially a longer incubation time would lead to apoptosis, which should be examined in future studies.

The treatment of SGC-7901 cells with a combination of itraconazole and 5-FU was able to markedly increase the number of cells in the $\mathrm{S}$ phase compared with treatment with itraconazole or 5-FU alone. This may be due to the cells being inhibited and arrested at the $\mathrm{S}$ phase, which consistent with the findings of previous studies (18-22).

According to American Joint Committee on Cancer (AJCC) staging system (23), all the patients in the present study were diagnosed with stage IV gastric cancer. A combination of 5-Fu and irinotecan was the most commonly used regimen for advanced gastric cancer according to the National Comprehensive Cancer Network guidelines (23). However, only 60 patients were enrolled during the 7-year period, as there were not many patients that were treated with itraconazole for mycotic infection during chemotherapy. This limited number of patients might have affected statistical accuracy, but it did not alter the outcomes of the study.

All 60 enrolled patients were diagnosed with advanced gastric cancer, and the final AJCC stage was stage IV. The stage IV patients are usually treated with a combination of 5-FU and irinotecan. Therefore, the majority of the patients were treated with a combination of 5-FU and irinotecan.

In the present study, the 5-year survival rate was very low $(0 \%)$, which is due total 60 patients presented with stage IV gastric cancer. These patients usually withdrew from treatments due to financial reasons.

Although it was demonstrated by the present study that itraconazole was able to inhibit proliferation and alter the cell cycle of gastric cancer cells, there is limited knowledge on the mechanism of action of itraconazole. Previous studies have reported that itraconazole was able to inhibit the angiogenesis of cancer by suppressing a number of signaling pathways such as inhibiting the binding of vascular endothelial growth factor (VEGF) to VEGF receptor 2 (VEGFR2) (5). In the present study, it was demonstrated that itraconazole was able to directly inhibit the proliferation of gastric cells.

The present study has a number of limitations. Due to funding and time constraints, it was not possible to perform the in vitro experiments using an additional gastric carcinoma cell line. However, the present study forms a preliminary analysis of the effects of itraconazole in conjunction with 5'FU. The authors will conduct further experiments as well as a phase I study to elucidate the underlying mechanisms of itraconazole and to confirm the conclusions in the present study.

In addition, the inhibitory concentrations of itraconazole and 5'FU might not be accurate, as the goodness of fit (itraconazole, $\mathrm{R}^{2}=0.919 ; 5-\mathrm{FU}, \mathrm{R}^{2}=0.961$ ) was not perfect (24). However, it was observed that the addition of itraconazole to 5-FU-based chemotherapy was able to improve the survival of patients with gastric cancer. The present study is a case-control study, and the number of cases treated with itraconazole was limited. Therefore, a randomized controlled trial is also required for further study.

In summary, treatment with itraconazole alone and in combination with 5-FU was able to inhibit the growth of gastric cancer cells in vitro and prolong the survival of patients with gastric cancer.

\section{Acknowledgements}

Not applicable.

\section{Funding}

No funding was received.

\section{Availability of data and materials}

The datasets used and/or analyzed during the current study are available from the corresponding author on reasonable request.

\section{Authors' contributions}

$\mathrm{KeL}$ and $\mathrm{KZ}$ performed the experimental procedures. WL and ZX collected the data. KeL, KZ, RY, CD and KaL interpreted the data and wrote the paper. KaL directed the research. All authors read and approved the final manuscript.

\section{Ethics approval and consent to participate}

The present study was approved by the Committee for the Conduct of Human Ethics Committee of the First Affiliated Hospital of Xi'an Jiaotong University, and all patients signed written informed consent forms.

\section{Patient consent for publication}

The patients have provided consent for the publication of their data.

\section{Competing interests}

The authors declare that they have no competing interests.

\section{References}

1. Bevan R, Young C, Holmes P, Fortunato L, Slack R and Rushton L; British Occupational Cancer Burden Study Group: Occupational cancer in Britain. Gastrointestinal cancers: Liver, oesophagus, pancreas and stomach. Br J Cancer 107 (Suppl 1): S33-S40, 2012.

2. Kim J, Tang JY, Gong R, Kim J, Lee JJ, Clemons KV, Chong CR, Chang KS, Fereshteh M, Gardner D, et al: Itraconazole, a commonly used antifungal that inhibits Hedgehog pathway activity and cancer growth. Cancer Cell 17: 388-399, 2010.

3. Kim J, Aftab BT, Tang JY, Kim D, Lee AH, Rezaee M, Kim J, Chen B, King EM, Borodovsky A, et al: Itraconazole and arsenic trioxide inhibit Hedgehog pathway activation and tumor growth associated with acquired resistance to smoothened antagonists. Cancer Cell 23: 23-34, 2013.

4. Sano T, Ozaki K, Kodama Y, Matsuura T and Narama I: Effects of the antifungal agent itraconazole on proliferative changes of the forestomach mucosa in alloxan-induced diabetic rats. Toxicol Pathol 37: 790-798, 2009. 
5. Nacev BA, Grassi P, Dell A, Haslam SM and Liu JO: The antifungal drug itraconazole inhibits vascular endothelial growth factor receptor 2 (VEGFR2) glycosylation, trafficking, and signaling in endothelial cells. J Biol Chem 286: 44045-44056, 2011.

6. Liu R, Li J, Zhang T, Zou L, Chen Y, Wang K, Lei Y, Yuan K, Li Y, Lan J, et al: Itraconazole suppresses the growth of glioblastoma through induction of autophagy: Involvement of abnormal cholesterol trafficking. Autophagy 10: 1241-1255, 2014.

7. Suzman DL and Antonarakis ES: High-dose itraconazole as a noncastrating therapy for a patient with biochemically recurrent prostate cancer. Clin Genitourin Cancer 12: e51-e53, 2014.

8. Aftab BT, Dobromilskaya I, Liu JO and Rudin CM: Itraconazole inhibits angiogenesis and tumor growth in non-small cell lung cancer. Cancer Res 71: 6764-6772, 2011.

9. Blaschke M, Cameron S, Goeschen C and Ramadori G: 5-FU schedules, serum 5-FU levels and their relationship to therapy response and toxicity in patients with gastrointestinal cancer. Int J Clin Pharmacol Ther 51: 56-58, 2013.

10. Cai J, Chen S, Zhang W, Wei Y, Lu J, Xing J and Dong Y: Proteomic analysis of differentially expressed proteins in 5-fluorouracil-treated human breast cancer MCF-7 cells. Clin Transl Oncol 16: 650-659, 2014.

11. Zhao L, Wientjes MG and Au JL: Evaluation of combination chemotherapy: Integration of nonlinear regression, curve shift isobologram, and combination index analyses. Clin Cancer Res 10: 7994-8004, 2004.

12. Pandita A, Kumar B, Manvati S, Vaishnavi S, Singh SK and Bamezai RN: Synergistic combination of gemcitabine and dietary molecule induces apoptosis in pancreatic cancer cells and down regulates PKM2 expression. PLoS One 9: e107154, 2014.

13. Scarano W, de Souza P and Stenzel MH: Dual-drug delivery of curcumin and platinum drugs in polymeric micelles enhances the synergistic effects: A double act for the treatment of multidrug-resistant cancer. Biomater Sci 3: 163-174, 2015.

14. Chou TC and Talalay P: Quantitative analysis of dose-effect relationships: The combined effects of multiple drugs or enzyme inhibitors. Adv Enzyme Regul 22: 27-55, 1984.

15. Singh NP and Stephens RE: Microgel electrophoresis: Sensitivity, mechanisms, and DNA electrostretching. Mutat Res 383: 167-175, 1997.

16. Gao W, Jiang L, Ge L, Chen M, Geng C, Yang G, Li Q, Ji F, Yan Q, Zou Y, et al: Sterigmatocystin-induced oxidative DNA damage in human liver-derived cell line through lysosomal damage. Toxicol In Vitro, 29: 1-7, 2015.
17. Eisenhauer EA, Therasse P, Bogaerts J, Schwartz LH, Sargent D, Ford R, Dancey J, Arbuck S, Gwyther S, Mooney M, et al: New response evaluation criteria in solid tumours: Revised RECIST guideline (version 1.1). Eur J Cancer 45: 228-247, 2009.

18. Nacev BA and Liu JO: Synergistic inhibition of endothelial cell proliferation, tube formation, and sprouting by cyclosporin A and itraconazole. PLoS One 6: e24793, 2011.

19. Antonarakis ES, Heath EI, Smith DC, Rathkopf D, Blackford AL, Danila DC, King S, Frost A, Ajiboye AS, Zhao M, et al: Repurposing itraconazole as a treatment for advanced prostate cancer: A noncomparative randomized phase II trial in men with metastatic castration-resistant prostate cancer. Oncologist 18: 163-173, 2013.

20. Rudin CM, Brahmer JR, Juergens RA, Hann CL, Ettinger DS, Sebree R, Smith R, Aftab BT, Huang P and Liu JO: Phase 2 study of pemetrexed and itraconazole as second-line therapy for metastatic nonsquamous non-small-cell lung cancer. J Thorac Oncol 8: 619-623, 2013

21. Kim DJ, Kim J, Spaunhurst K, Montoya J, Khodosh R, Chandra K, Fu T, Gilliam A, Molgo M, Beachy PA and Tang JY: Open-label, exploratory phase II trial of oral itraconazole for the treatment of basal cell carcinoma. J Clin Oncol 32: 745-751, 2014.

22. Tsubamoto H, Sonoda T, Yamasaki M and Inoue K: Impact of combination chemotherapy with itraconazole on survival of patients with refractory ovarian cancer. Anticancer Res 34: 2481-2487, 2014

23. Ajani JA, D'Amico TA, Almhanna K, Bentrem DJ, Chao J, Das P, Denlinger CS, Fanta P, Farjah F, Fuchs CS, et al: Gastric Cancer, Version 3.2016, NCCN Clinical Practice Guidelines in Oncology. J Natl Compr Canc Netw 14: 1286-1312, 2016.

24. What is a good value for R-squared? https://people.duke. edu/ rnau/rsquared.htm. Accessed May 7, 2016.

c) (i) $\Theta$ This work is licensed under a Creative Commons Attribution-NonCommercial-NoDerivatives 4.0 International (CC BY-NC-ND 4.0) License. 